\title{
The protective role of green tea and garlic against the eryptosis induced by aging in albino rats
}

\author{
Gamal H. El-Sokkary, Al Shaimaa A. I. Alghriany* and Mona M. Atia
}

*Correspondence: alshaimaa84@yahoo.com

Department of Zoology Faculty of Science, Assiut University Assiut, 71516 Egypt.

\begin{abstract}
Objective: Green tea, is particularly rich in flavonoids, which are strong antioxidants. Also, garlic possesses both antioxidant and anti-inflammatory action in several oxidative stress conditions. Our aim was to evaluate the effects of aging as biological vital process on the eryptosis and erythrocytes alterations in albino rats and the ability of the green tea and garlic extract to alleviate those effects.

Materials \& methods: Four groups of both male and female rats [young (3 months-old), aged (26 months-old), aged+green tea $(200 \mathrm{mg} / \mathrm{kg})$ and aged +garlic $(100 \mathrm{mg} / \mathrm{kg})]$ were used. Blood smears prepared and stained by haematoxlyin and eosin for alteration in RBCs detection and acridine orange for eryptosis detection.

Results: Blood smears showed that aging in males and females resulted in the appearance of pathologic types of RBCs as Tear drop like cells (Tr), Sickle cells (Sk), Amoeboid RBCs (Am), Target cells (Tg), Crenated cells $(\mathrm{Cr})$, and Rouleaux appearance. Treatment with green tea decreased these alterations significantly in females while garlic decreased it significantly in both male and female groups. Moreover, eryptosis analyzed by Acridine orange stain showed increased number of eryptosis in RBCs in aging but decreased significantly by the treatment with both green tea and garlic in both genders.

Conclusion: Administration of the green tea extract and garlic orally was able to reinstate the erythrocytes alterations and eryptotic level as biomarkers for the aging process evaluation and treatment

Keywords: Rats; eryptosis, target cells, green tea, garlic
\end{abstract}

\section{Introduction}

The aging process is a unique feature of the life cycle of virtually all multicellular organisms including many physiological actions to maintain homeostasis and resulting in death. Although numerous hypotheses have been advanced to explain the aging process, many lacks sufficient empirical support to merit serious consideration [1]. It was postulated that, aging results from the accumulation of deleterious effects caused by free radicals and the ability of an organism to cope with cellular damage induced by reactive oxygen species (ROS) plays a vital role in determining organismal lifespan [2]. ROS production by mitochondria and increased 8-oxo-dG content in the mtDNA are frequently detected in aged tissues. This suggesting that progressive accumulation of oxidative DNA damage is a contributory factor to the aging process [3]. Consistently, [4] reported that increased oxidative damage in cells is associated with aging.

Blood is a good indicator to determine the health of an organism and hematological parameters are important in diagnosing the functional status of exposed animals to toxicants $[5,6,7]$. Eryptosis is considered as cellular defense mechanism by which the organism can get ride from dead and damaged red blood cells in natural and stressful conditions [8]. Also, the erythrocytes alterations in most of animal models were used as biomarkers for the toxicological studies and antioxidants action estimation [9].

Garlic (Allium sativum) is important dietary and has medicinal role for centuries. The suggested pharmacological effects of garlic are hypolipidemic, hypoglycemic, anticoagulant, antihypertensive, antimicrobial, anticancer and antitumor, as an antidote for heavy metal poisoning, hepatoprotective and as an immunomodulator [10]. Organosulfur compounds, present 
in garlic, have significant antioxidant effects as well [11].

Green tea (Camellia sinensis) is an extremely popular drink in eastern countries, and green tea polyphenols are natural plant flavonoids found in the tea plant leaves. Polyphenol antioxidants are known as catechins. The major tea catechins include epicatechin (EC), epigallocatechin (EGC), EC gallate (ECG) and EGC gallate (EGCG). Epigallocatechingallate is the most active antioxidant of the tea catechins and is responsible for the "green tea effect." $[12,13]$.

It was reported that, the polyphenols in green tea can neu tralize free radicals and may reduce or even help to prevent some of the damage caused by reactive oxygen species [14]. On the other hand, tea polyphenols have the ability to participate in vitamin E recycling [15]. Because of the presence of other antioxidant constituents in the green tea extract, it is more stable than pure epigallocatechingallate; one of the major constituents of green tea $[16,17]$.

The aim of this study was to investigates the role of the garlic and green tea extract as antioxidants against the eryptosis and erythrocytes alterations recorded in the aged albino rats with spot the light on their potential

\section{Materials and methods Animals}

A total number of 160 rats ( 80 males and 80 females) used in this study. 20 males and 20 females with initial ages of 3 months (young), 60 males and 60 females with the initial age of 22 months (aged). They were purchased from Assiut University Joint Animal Breeding Unit. Care and treatment of animals was approved and practices were performed according to approval of ethics regulation at the Assiut University. The animals were kept at temperature of $23 \pm 2^{\circ} \mathrm{C}$ and light cycle of 12:12 hours light:dark. All animals were given free access to standard chow and tap water.

\section{Green tea and garlic preparations}

The leaves of green tea of Camellia Sinensis was purchased from (Twinings of London, England). The leaves were boiled in distilled water (1:10 w/v) 5 min twice. The solution was called unfiltered, then filtrates were combined, concentrated, and lyophilized. Ten grams of lyophilized aqueous extract were soaked in 1 liter of boiling distilled water to make $1 \%$ solution. The solution designated as green tea extract (GTE) was orally administered to rats by gastric tube at a dose of $200 \mathrm{mg} / \mathrm{Kg}$ [18].

Garlic (Tomex 200 mg tab) was purchased from Sekem Pharmacy, Egypt. It was dissolved in distilled water and was given orally to rats by gastric tube at a dose of $100 \mathrm{mg} / \mathrm{kg}$ [19].

\section{Experimental design}

The animals were divided into 4 groups for each gender, 20 rats for each; group 1; ( 3 mon- old) served as young control group (y. cont), group2; (26 mon-old) served as old group (Ag), group 3; (26 mon-old) orally received $200 \mathrm{mg} / \mathrm{kg}$ green tea extract per day $(\mathrm{Ag}+\mathrm{GT})$, and group 4; (26 mon-old) orally received $100 \mathrm{mg} / \mathrm{kg}$ garlic per day $(\mathrm{Ag}+\mathrm{Gr})$. The administration of green tea and garlic was repeated daily for 4 months.

\section{Blood smear preparation and RBCs alterations}

Blood samples collected, and smears were dried, fixed in absolute methanol for $10 \mathrm{~min}$, and stained by haematoxylin and eosin. Slides were selected on the basis of staining quality and randomized to be scored blindly. In each group, 10,000 cells (minimum of 1,000 cells per slide) were examined under $40 x$ objective to identify morphologically altered red blood corpuscles according to the method by $[\mathbf{7 , 2 0 ]}$. Morphological alterations of red blood cells such as acanthocytes, teardroplike cells, sickle cells, swollen cells, crenated cells and alterations of nuclear morphology were recorded.

\section{Eryptosis detection}

Eryptotic red blood corpuscles were detected by acridine orange (AO) (Cat. No. A1031; Life Technologies, Carlsbad, (A, USA) staining. A modification of the protocol reported by [21] was used to detect the apoptosis in red blood cells. Blood smears were prepared on clean glass slides, washed in $1 \times$ PBS ( $\mathrm{pH}=7.2)$, then AO staining solution $(17 \mu \mathrm{g} / \mathrm{IO}$ in $1 x$ PBS) was put on the slides for $30 \mathrm{~min}$ in the dark. Then, the slides were washed four times for 30 min with $1 \times$ PBS to decolorize and fixed in 4\% paraformaldehyde in $1 \times$ PBS for 5 $\min$ [22]. Finally, eryptotic red blood corpuscles were scored under a fluorescence microscope (BX50; Olympus, Tokyo, Japan) equipped with a digital still camera (DP70, Olympus).

\section{Statistical analysis}

Analysis of variance was performed using SPSS software [23] to analyze the normal distributed data. For not normal distributed data, Kruskal - Wallis and Mann - Whitney were used.

\section{Results \\ RBCs alterations}

The H\&E stained blood smears of male and female rats in all groups shown in Figures 1 and 2. In the young control group (y. cont.), the blood smear represents the normal structure of erythrocytes. The blood is composed of rounded biconcave non-nucleated erythrocytes (Er) and several types of leucocytes (L) as shown in Figures $\mathbf{1}$ a and $2 \mathrm{a}$ ).

In male rats, aging resulted in morphological changes in the RBCs and some pathologic types of RBCs were detected. The major alterations in the aged male rats are represented in Figures $\mathbf{1} \mathbf{b}$ and $\mathbf{1 c}$ ) as: Tear drop like cells (Tr); where the shape of the RBCs look like tear with pointed apices, Sickle cells (Sk) which vary in shape between genuine sickles, ellipsoidal and boat shaped, Acanthocytes (Ac) which have projections of different length that are unevenly spaced of the surface of the RBCs, Amoeboid RBCs (Am) which look like Amoeba sp. and Target cells (Tg) in which the RBCs have a dark center surrounded by a light band that again is encir- 


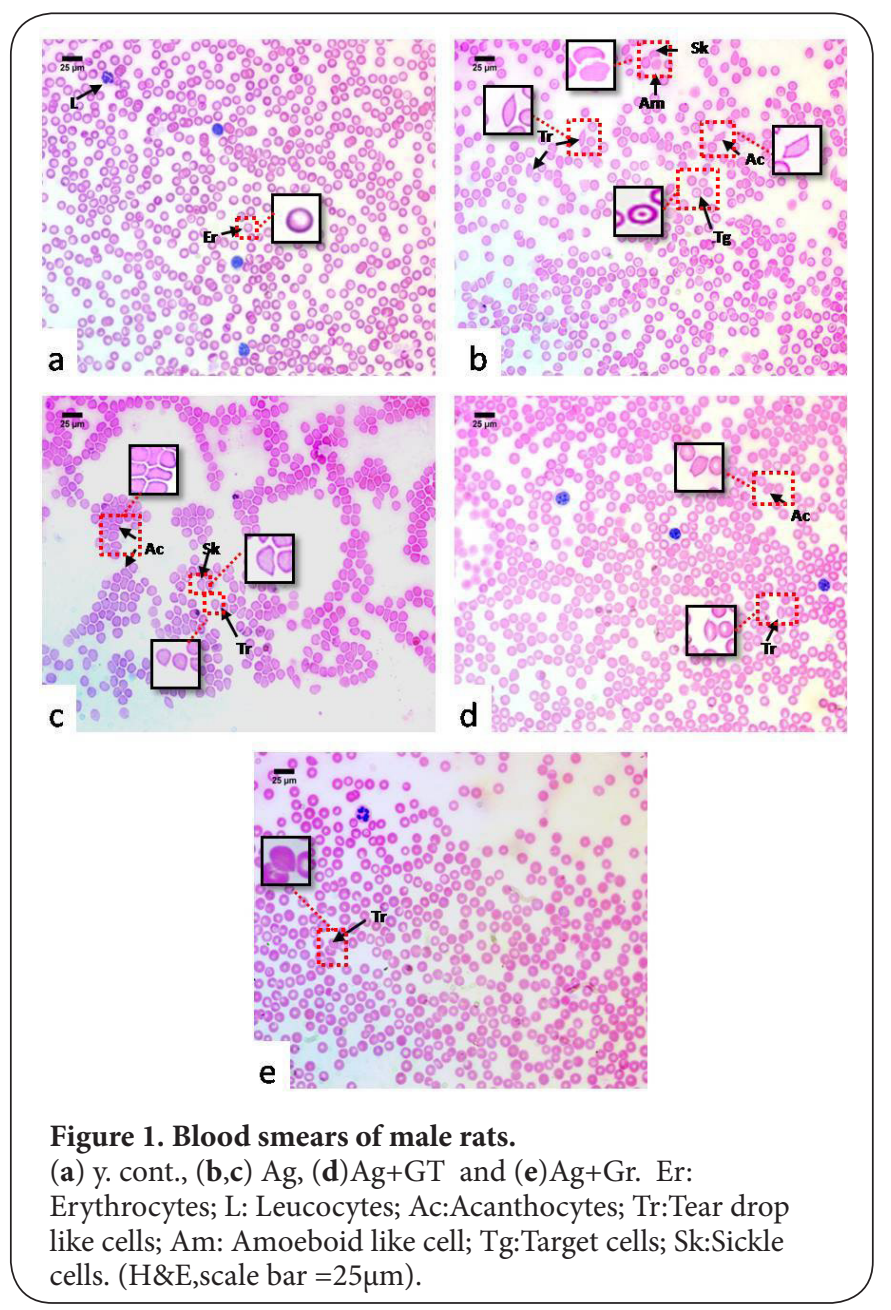

cled by a darker ring resembling a shooting target. Also, the appearance of sticking cells together in a chain like shape which are called Rouleaux appearance of RBCs was detected as shown in Figure $1 \mathrm{c}$.

Quantitatively, the percentage of RBCs alterations in aged male group increased significantly $(P<0.05)$ by $131.8 \%$ when compared with young control group animals (Table 1).

By treating the aged male rats with green tea, the alterations decreased when compared with those of Ag group. The decrease was $23.5 \%$ and non-significant (Table 1). Morphologically, the alterations represented as Acanthocytes (Ac) and Tear drop like cells ( $\mathrm{Tr}$ ) as shown in Figure $\mathbf{1 d}$.

The treatment of the aged male rats with garlic markedly decreased the RBCs alterations when compared with those of Ag male group (Table 1). This decrease was $43.1 \%$ and statistically significance $(P<0.05)$. Morphologically, the alterations represented by Tear drop like cells ( $\mathrm{Tr}$ ) as in Figure 1e. There were non-significant differences among the young control and the two Aged- treated groups (Ag+GT and Ag+Gr) as shown in Table 1. Also, the difference in the percentage of $\mathrm{RBC}$ s alterations between $\mathrm{Ag}+\mathrm{GT}$ group and $\mathrm{Ag}+\mathrm{Gr}$ group

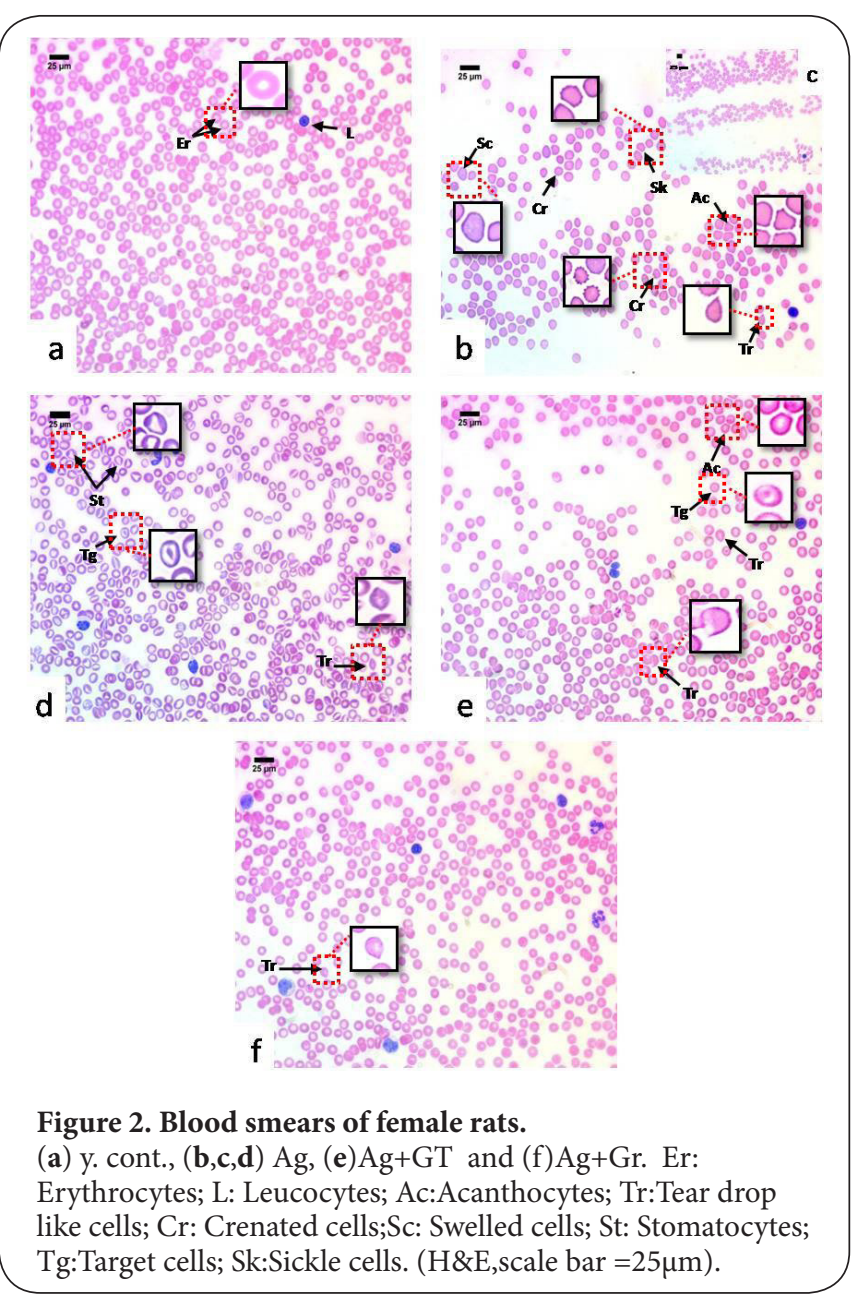

was non-significant (Table 1).

In female rats, aging increased the percentage of RBCs alterations significantly $(P<0.001)$ by $305.0 \%$ when compared with young animals (Table 1 ). These alterations represented in Figures $\mathbf{2} \mathbf{b}$ and $\mathbf{2 d}$ ) by Crenated cells $(\mathrm{Cr})$, where the RBCs developed irregular cell surface with numerous projections more than that present in Acanthocytes, Stomatocytes (St) which characterized by an enlarged or slit like area of central pallor that resembles a mouth, Swelled cells (Sc). In addition to Tear drop like cells (Tr), Acanthocytes (Ac), Sickle cells (Sk), Target cells ( $\mathrm{Tg}$ ) and the Rouleaux appearance of RBCs were observed in Figure 2c.

The treatment of aged females with green tea significantly decreased $(P<0.05)$ the percentage of RBCs alterations than that in aged female group by $48.2 \%$ as shown in (Table 1 ). The alterations represented as Acanthocytes (Ac), Target cells ( $\mathrm{Tg}$ ) and Tear drop like cells ( $\mathrm{Tr}$ ) as shown in Figure 2e. Administration of garlic markedly decreased the RBCs alterations by $67.9 \%$ than that of Ag female group. Statistically, this decrease was significant $(P<0.001)$. As shown in Figure $\mathbf{2 f}$, the alterations represented by Tear drop like cells (Tr). There were 
non-significant differences among young control and the two aged- treated groups $(\mathrm{Ag}+\mathrm{GT}$ and $\mathrm{Ag}+\mathrm{Gr})$. Also, the difference between the two aged - treated groups was non- significant as shown in Table 1.

In comparison between the percentage of RBCs alterations in male and female rats, there were non-significant differences in the percentage between y cont. males and females. In contrast, the percentage of alterations in aged females increased significantly $(P<0.01)$ than those of male ones. The differences among the two aged - treated animals ( $\mathrm{Ag}+\mathrm{GT}$ and $\mathrm{Ag}+\mathrm{Gr}$ ) in both males and females were non-significant (Table 1).

\section{Eryptosis in RBCs}

The eryptotic RBCs are stained with Acridine Orange $(A O)$ and appear in light green color by the fluorescence microscope as shown in Figure 3.

In male rats, aging resulted in increase the number of $\mathrm{AO}$ positive eryptotic RBCs. This increase was significant $(P<0.001)$ by $233.3 \%$ in Ag group (Figure $\mathbf{3 b}$ ) when compared with young control group animals (Table 2, Figure 3a).

The treatment of aged male rats with green tea markedly decreased the number of eryptotic RBCs by $44.0 \%$ when compared with those of Ag group. This decrease was significant $\mathrm{P}<0.01$ (Table 2, Figure 3c). Also, treating the aged rats with garlic decreased the number of eryptotic RBCs significantly $(\mathrm{P}<0.05)$ by $26.0 \%$ when compared with Aged rats group (Table 2, Figure 3d).

There was non-significant difference in the number of eryptotic RBCs occurred between the two aged-treated groups $(\mathrm{Ag}+\mathrm{GT}$ and $\mathrm{Ag}+\mathrm{Gr})$. The comparison between young control rats and $A g+G T$ ones revealed non-significant difference between them. In contrast, there was significant increase $(\mathrm{P}<0.01)$ was between young control rats group and $\mathrm{Ag}+\mathrm{Gr}$ ones (Table 2 ).

In female rats, there was a significant increase $(P<0.001)$ in the number of eryptotic RBCs by $103.7 \%$ in aged rats group (Figure 3f) when compared with young control group ones (Table 2, Figure 3e).

Table 1. Means of $\%$ of RBCs alteration \pm SE, stimulation and/or inhibition $\%$ in young, aged and aged-treated male and female rats.

\begin{tabular}{|c|c|c|c|c|c|}
\hline Measurement & & Male & & emale & \\
\hline Groups & alterations & $\begin{array}{l}\text { Inhibition \%(I) } \\
\text { Or } \\
\text { Stimulation \%(S) }\end{array}$ & alterations & $\begin{array}{l}\text { Inhibition\% (I) } \\
\text { or } \\
\text { Stimulation\%(S) }\end{array}$ & 8 vs. + \\
\hline y. cont & $4.4 \pm 0.68^{\mathrm{a}}$ & - & $4.0 \pm 0.68^{a}$ & - & $P>0.05$ \\
\hline $\mathrm{Ag}$ & $10.2 \pm 1.63^{b}$ & $\mathrm{~S}=131.8 \mathrm{vs} . \mathrm{y} \cdot \mathrm{cont}$. & $16.2 \pm 2.53^{\mathrm{b}}$ & $\mathrm{S}=305$ vs. y. cont. & $\mathrm{P}<0.01$ \\
\hline $\mathrm{Ag}+\mathrm{GT}$ & $7.8 \pm 1.43^{\mathrm{abc}}$ & $\mathrm{I}=23.5$. vs. $\mathrm{Ag}$ & $8.4 \pm 1.462^{a}$ & $\mathrm{I}=48.15$ vs. $\mathrm{Ag}$ & $\mathrm{P}>0.05$ \\
\hline $\mathrm{Ag}+\mathrm{Gr}$ & $5.8 \pm 0.929^{\mathrm{ac}}$ & $\begin{array}{l}\mathrm{I}=43.1 \text { vs. } \mathrm{Ag} \\
\mathrm{S}=25.6 \text { vs. } \mathrm{Ag}+\mathrm{GT}\end{array}$ & $5.2 \pm 0.917^{\mathrm{a}}$ & $\begin{array}{l}\mathrm{I}=67.9 \text { vs. } \mathrm{Ag} \\
\mathrm{S}=38.1 \text { vs. } \mathrm{Ag}+\mathrm{GT}\end{array}$ & $\mathrm{P}>0.05$ \\
\hline
\end{tabular}

Table 2. Means of eryptotic RBCs \pm SE, stimulation and/or inhibition $\%$ in young, aged and aged- treated male and female rats.

\begin{tabular}{|c|c|c|c|c|c|}
\hline Measurement & & Male & & emale & \\
\hline Groups & $\begin{array}{l}\text { Eryptotic } \\
\text { RBCs }\end{array}$ & $\begin{array}{l}\text { Inhibition \%(I) } \\
\text { Or } \\
\text { Stimulation \%(S) }\end{array}$ & $\begin{array}{l}\text { Eryptotic } \\
\text { RBCs }\end{array}$ & $\begin{array}{c}\text { Inhibition } \%(\mathrm{I}) \\
\text { or } \\
\text { Stimulation } \%(\mathrm{~S})\end{array}$ & 8 vs. 9 \\
\hline y. cont & $1.5 \pm 0.27^{\mathrm{a}}$ & - & $2.7 \pm 0.42^{\mathrm{a}}$ & - & $\mathrm{P}>0.05$ \\
\hline $\mathrm{Ag}$ & $5 \pm 0.6^{b}$ & $\mathrm{~S}=233.3 \mathrm{vs} . \mathrm{y} \cdot \mathrm{cont}$. & $5.5 \pm 0.37^{b}$ & $\mathrm{~S}=103.7$ vs. y.cont. & $\mathrm{P}>0.05$ \\
\hline $\mathrm{Ag}+\mathrm{GT}$ & $2.8 \pm 0.39^{a}$ & $\mathrm{I}=44.0$ vs. $\mathrm{Ag}$ & $3.1 \pm 0.35^{\mathrm{a}}$ & $\mathrm{I}=43.6$ vs. $\mathrm{Ag}$ & $\mathrm{P}>0.05$ \\
\hline $\mathrm{Ag}+\mathrm{Gr}$ & $3.7 \pm 0.42^{a}$ & $\begin{array}{l}\mathrm{I}=26.0 \text { vs. } \mathrm{Ag} \\
\mathrm{S}=32.4 \text { vs. } \mathrm{Ag}+\mathrm{GT}\end{array}$ & $3.2 \pm 0.41^{\mathrm{a}}$ & $\begin{array}{l}\mathrm{I}=41.8 \mathrm{vs} . \mathrm{Ag} \\
\mathrm{S}=3.2 \mathrm{vs} . \mathrm{Ag}+\mathrm{GT}\end{array}$ & $\mathrm{P}>0.05$ \\
\hline
\end{tabular}


The treatment of the aged rats by green tea decreased the number of eryptotic RBCs significantly $(P<0.001)$ by $43.6 \%$ when compared with aged rats (Table 2, Figure $\mathbf{3 g}$ ). Also, treating of the aged rats by garlic decreased the number of AO-positive RBCs significantly $(\mathrm{P}<0.001)$ by $41.8 \%$ when compared with aged ones (Table 2, Figure $3 \mathrm{~h}$ ).

There was non-significant difference occurred between the two aged - treated groups ( $\mathrm{Ag}+\mathrm{GT}$ and $\mathrm{Ag}+\mathrm{Gr}$ ). When comparing the number of eryptotic RBCs in the aged-treated groups with the young control rats, there were non-significant difference occurred (Table 2).

In comparison between the number of eryptotic RBCs in male and female rats, there were non-significant differences between each group in male rats and its corresponding in female's ones (Table 2).

\section{Discussion}

In this study, we analysed morphological alterations and

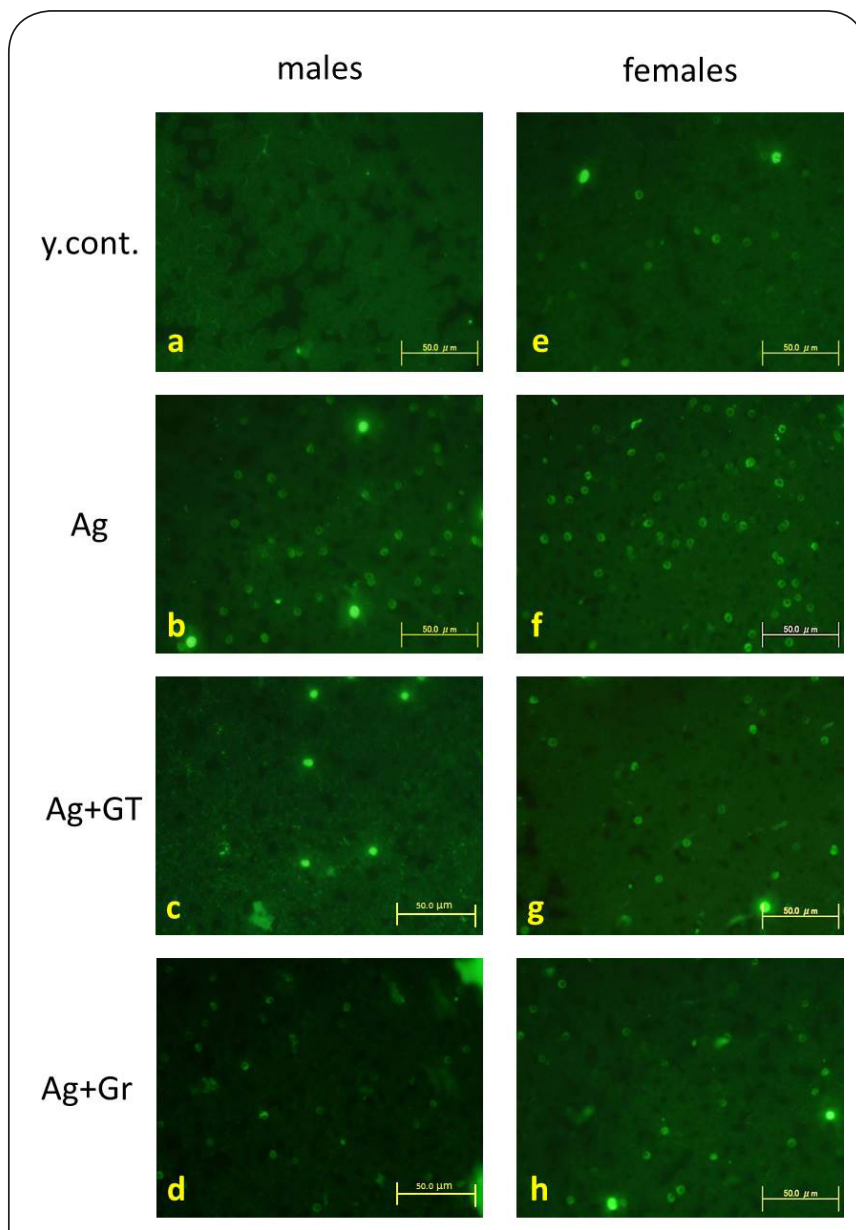

Figure 3. The eryptotic RBCs of rats.

(a) y.cont. male; (b) Ag male; (c) Ag+GT male; (d) Ag+Gr;

(e) y.cont. female; (f) Ag female; (g)Ag+GT female; (h)Ag+Gr female in light green color under the fluorescence microscope

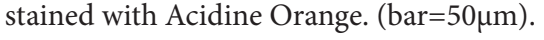

eryptotic cell death induced by aging in RBCs of male and female rats and the protective role of green tea and garlic as antioxidants. Eryptosis as well as RBCs alterations increased significantly in aged male and female rats reporting an evidence for the importance of erythrocytes to act as model cells for the study of aging and age-related diseases $[\mathbf{9 , 2 4 ]}$. It was reported that, lack of nucleus and mitochrondria, inability to synthesise new protein and degradation of detoxifying enzymes makes RBCs uniquely vulnerable to oxidative stress $[9,24]$.

Recently, oxidative stress is now known to be a major factor in the development of most pathological events associated with aging and RBCs are the first cells in the body to be exposed to stressful stimuli [25]. Free radicals can directly damage RBCs membranes by peroxidation of membrane polyunsaturated fatty acids and cause considerable changes in the structural organization and functions of cell membranes and making the membrane leaky [26], which may be lead to suicidal death of erythrocytes (eryptosis). Eryptosis increased significantly in male and female rats by aging due to oxidative stress response. Besides caspase activation after oxidative stress, two signaling pathways converge to trigger eryptosis; (a) formation of prostaglandin E2 leads to activation of $\mathrm{Ca} 2+-$ permeable cation channels, and (b) the phospholipase A2 -mediated release of platelet-activating factor activates a sphingomyelinase, leading to formation of ceramide. Both activation of Ca2+ activity and enhanced ceramide levels lead to cell shrinkage whish considered as the first signs of eryptosis $[\mathbf{2 7}, \mathbf{2 8}]$.

Many of RBCs alterations were observed and represented in aged males and females as Tear drop like cells, Sickle cells, Acanthocytes, Amoeboid RBCs, Target cells, Crenated cells, Stomatocytes, Swelled cells. Also, the appearance of sticking cells together in a chain like shape which are called Rouleaux appearance of RBCs. Those alterations were similar to these recorded due to apoptosis [29], after exposure to gavage dosing with 2-butoxyethanol [30], exposure to lead [31], and in Rett syndrome [32].

Membrane changes after oxidative stress were used as biochemical changes will ultimately address the cause and treatment of disease, so that, RBCs are probably the most adaptable cells in our bodies, and due to their short life span, may form a vital indicator of health [33].

Transition of normal discoid erythrocytes to crenated forms (echinocytes) is often induced by the same factors which cause apoptosis of blood cells, e.g., ionizing radiation and other reactive oxygen intermediate-inducing agents, exogenous oxidants, in vitro aging conditions, cytosolic calcium increase, etc. Characteristic changes in cell shape in oxidant-treated $\mathrm{RBCs}$ are of value for interpreting the membrane alterations occurring in leukocyte apoptosis [31]. Our results revealed an increased RBCs alterations and percentage of apoptosis in aged female rats than that in male ones. This result was in a line with [34] who found that female rats were more susceptible to oxidative damage than males. 
The treatment of the aged groups in our study with green tea and garlic helped in decrease the level of alterations and eryptosis in RBCs to the levels of young control group [35] reported that Garlic and garlic extracts, through their antioxidant activities, have been reported to provide protection against free radical damage in the body. Consumption of garlic decreases oxidation reactions. It is quite possible that reduced peroxidation processes due to garlic consumption may play a part in some of the beneficial effects of garlic in elderly subjects [36]. Among many active compounds of garlic is allicin which reported to fight against different pathological conditions, act as a metal chelator and can protect the cell from oxidative stress [37]. The role of allicin in the amelioration of the early death of erythrocytes during chronic exposure to $\mathrm{Pb} 2+$ in mice was evaluated by $[38,39]$, have reported that green tea (GT) by scavenging the free radicals directly in rats may reduce the utilization of glutathione (GSH) and thereby exhibiting an increase in the GSH content in diabetic rats treated with green tea extract which offers a good explanation of the significant increase in the GSH levels in green tea treated aged rats compared to that of non-treated aged rats. The antioxidant potential of GT polypehonls are reported to be equally as effective as vitamin $C$ and $E$ [40] indicated the protective role of GTE on lead acetate induced hemolysis both in vitro and in vivo condition using mice model.

Ghashghaeinia et al. [41] found that the susceptibility to eryptosis increases with the age and this effect due to enhanced sensitivity to oxidative stress. Perrone et al., [42] cleared that when erythrocytes were incubated in medium containing a number of oxidizing agents, iron release and the Fenton reaction led to hydroxyl radical formation causing red cell damage. If oxidative stress exceeds the antioxidant power of enzyme and non-enzymatic factors, membranes are denatured and lipid peroxidation occurs. These data were confirmed with our previous research [43] in which we found that aging increased the level of LPO which considered a sign of oxidative stress caused by aging and the antioxidant properties of green tea and garlic ameliorated these changes. In the absence of efficient protection by antioxidant factors oxidative stress therefore appears to be responsible for release of iron in a reactive form, predisposing red cells to haemolysis through formation of senescence antigen. Prior to senescence, erythrocytes may experience injury, which may compromise their integrity and survival. Under this condition the affected erythrocyte may undergo suicidal death or eryptosis [42]. Lang et al., [26] showed that Antioxidantsmay protect erythrocytes from oxidative stress and thus presumably from eryptosis.

\section{Conclusion}

In conclusion, our results reported that aging induced hematological responses, such as eryptosis and morphological alterations in RBCsas Tear drop like cells, Sickle cells, Amoeboid RBCs, Target cells, Crenated cells, and Rouleaux appearance. These alterations increased significantly in females than males.
The treatment of the aging rats with green tea extract and garlic decreased the number of eryptotic and altered RBCs in both sexes. In comparison between eryptotic RBCs percentage in male and female rats, there was non-significant difference between each group in male rats and its corresponding in female's ones. So, we can consider that green tea and garlic have a noticeable role in decreasing the number of eryptotic and altered RBCs caused by aging process.

\section{Competing interests}

The authors declare that they have no competing interests.

\section{Authors' contributions}

\begin{tabular}{|l|c|c|c|}
\hline Authors' contributions & GHE & ASA & MMA \\
\hline Research concept and design & $\checkmark$ & $\checkmark$ & -- \\
\hline Collection and/or assembly of data & $\checkmark$ & $\checkmark$ & -- \\
\hline Data analysis and interpretation & $\checkmark$ & $\checkmark$ & -- \\
\hline Writing the article & $\checkmark$ & $\checkmark$ & -- \\
\hline Critical revision of the article & $\checkmark$ & $\checkmark$ & $\checkmark$ \\
\hline Final approval of article & $\checkmark$ & $\checkmark$ & -- \\
\hline Statistical analysis & $\checkmark$ & $\checkmark$ & -- \\
\hline
\end{tabular}

Acknowledgements

The authors like to thank Dr. Alaa El-Din H. Sayed Associate Prof. of Fish Biology, Department of Zoology, Faculty of Science, Assiut University for his efforts and endless help in performing this work.

Publication history

Editor: Giuseppe Musumeci, University of Catania, Italy. Received: 08-May-2018 Final Revised: 10-July-2018 Accepted: 16-July-2018 Published: 03-Aug-2018

\section{References}

1. Sohal RS, Mockett RJ and Orr WC. Mechanisms of aging: an appraisal of the oxidative stress hypothesis. Free Radic Biol Med. 2002; 33:575-86. | Article | PubMed

2. Harman D. Aging: a theory based on free radical and radiation chemistry. J Gerontol. 1956; 11:298-300. | PubMed

3. Maynard S, Schurman SH, Harboe C, de Souza-Pinto NC and Bohr VA. Base excision repair of oxidative DNA damage and association with cancer and aging. Carcinogenesis. 2009; 30:2-10. | Article | PubMed Abstract | PubMed FullText

4. Hamilton ML, Van Remmen H, Drake JA, Yang H, Guo ZM, Kewitt K, Walter CA and Richardson A. Does oxidative damage to DNA increase with age? Proc Natl Acad Sci U S A. 2001; 98:10469-74. | Article | PubMed Abstract | PubMed FullText

5. Joshp PK, Bose M and Harish D. Changes in certain haematological parameters in a siluroid cat fish Clarias batrachus (Linn) exposed to cadmium chloride. Pollution Research. 2002; 21:129-31.

6. Mekkawy IA, Mahmoud UM and Sayed Ael D. Effects of 4-nonylphenol on blood cells of the African catfish Clarias gariepinus (Burchell, 1822). Tissue Cell. 2011; 43:223-9. | Article | PubMed

7. Zbidah M and Aleppo S. Mechanisms of Apoptotic Death of Red Blood Cells Induced by Environmental Contaminants and Natural Products. 2014.

8. Sayed A E D H, Zaki R M, El-Dean A M K and Abdulrazzaq A Y. The biological activity of new thieno [2, 3-c] pyrazole compounds as anti-oxidants against toxicity of 4-nonylphenol in Clarias gariepinus. Toxicology reports, 2015; 2:1445-1453. | Article

9. Pandey KB and Rizvi SI. Markers of oxidative stress in erythrocytes and plasma during aging in humans. Oxid Med Cell Longev. 2010; 3:2-12. I 
Article | PubMed Abstract | PubMed FullText

10. Petropoulos S, Di Gioia F and Ntatsi G. Vegetable Organosulfur Compounds and their Health Promoting Effects. Curr Pharm Des. 2017. 23:2850-2875. | Article | PubMed

11. Banerjee SK, Maulik M, Manchanda SC, Dinda AK, Das TK and Maulik SK. Garlic-induced alteration in rat liver and kidney morphology and associated changes in endogenous antioxidant status. Food Chem Toxicol. 2001; 39:793-7. | Article | PubMed

12. Sayed AEH and Soliman HAM. Modulatory effects of green tea extract against the hepatotoxic effects of 4-nonylphenol in catfish (Clarias gariepinus). Ecotoxicol Environ Saf. 2018; 149:159-165. | Article | PubMed

13. Xu Y, Zhang JJ, Xiong L, Zhang L, Sun D and Liu H. Green tea polyphenols inhibit cognitive impairment induced by chronic cerebral hypoperfusion via modulating oxidative stress. J Nutr Biochem. 2010; 21:741-8. | Article I PubMed

14. Nugala B, Namasi A, Emmadi P and Krishna PM. Role of green tea as an antioxidant in periodontal disease: The Asian paradox. J Indian Soc Periodontol. 2012; 16:313-6. | Article | PubMed Abstract | PubMed FullText

15. Intra J and Kuo SM. Physiological levels of tea catechins increase cellular lipid antioxidant activity of vitamin $C$ and vitamin $E$ in human intestinal caco-2 cells. Chem Biol Interact. 2007; 169:91-9. | Article | PubMed Abstract | PubMed FullText

16. Gad SB and Zaghloul DM. Beneficial effects of green tea extract on liver and kidney functions, ultrastructure, lipid profile and hematological parameters in aged male rats. Global Vet. 2013; 11:191-205.

17. Thomas A, Thakur S and Habib R. Comparison of Antimicrobial Efficacy of Green Tea, Garlic with Lime, and Sodium Fluoride Mouth Rinses against Streptococcus mutans, Lactobacilli species, and Candida albicans in Children: A Randomized Double-blind Controlled Clinical Trial. Int J Clin Pediatr Dent. 2017; 10:234-239. | Article | PubMed Abstract | PubMed FullText

18. Mohamadin AM, Mariee AD, El-Hefnawy HM and Fath El-Bab M. Hypoglycemic activity of green tea extract in streptozotocin induced diabetic rats. Arab J Lab Med. 2003; 29:397-400.

19. Samar A A and Shireen A M. Distribution of Cyclooxygenase-2 (COX- 2) in the Liver of Adult Male Albino Rats after Supplementation of Sodium Arsenite with or without Allium Sativum(Garlic). Egypt. J. Histol. 2010; 33: $541-551$.

20. al-Sabti $\mathrm{K}$ and Metcalfe $\mathrm{CD}$. Fish micronuclei for assessing genotoxicity in water. Mutat Res. 1995; 343:121-35. | Article | PubMed

21. Sayed Ael D, Watanabe-Asaka T, Oda S and Mitani H. Apoptosis and morphological alterations after UVA irradiation in red blood cells of p53 deficient Japanese medaka (Oryzias latipes). J Photochem Photobiol B. 2016; 161:1-8. | Article | PubMed

22. Sayed A E D H, Zaki R M, El-Dean A M K and Abdulrazzaq A Y. The biological activity of new thieno [2,3-c] pyrazole compounds as anti-oxidants against toxicity of 4-nonylphenol in Clarias gariepinus. Toxicology reports, 2015; 2:1445-1453. | Article

23. SPSS. SPSS for Windows. SPSS Inc. Headquarters, Chicago. 1998.

24. Panneerselvam S, Packirisamy RM, Bobby Z, Elizabeth Jacob S and Sridhar MG. Soy isoflavones (Glycine max) ameliorate hypertriglyceridemia and hepatic steatosis in high fat-fed ovariectomized Wistar rats (an experimental model of postmenopausal obesity). J Nutr Biochem. 2016; 38:57-69. | Article | PubMed

25. Pandey KB and Rizvi SI. Biomarkers of oxidative stress in red blood cells. Biomed Pap Med Fac Univ Palacky Olomouc Czech Repub. 2011; 155:1316. | Pdf | PubMed

26. Devaud LL, Matthews DB and Morrow AL. Gender impacts behavioral and neurochemical adaptations in ethanol-dependent rats. Pharmacol Biochem Behav. 1999; 64:841-9. | Article | PubMed

27. Lang F, Lang KS, Lang PA, Huber SM and Wieder T. Mechanisms and significance of eryptosis. Antioxid Redox Signal. 2006; 8:1183-92. | Article | PubMed
28. Maccio $A$ and Madeddu C. Management of anemia of inflammation in the elderly. Anemia. 2012; 2012:563251. | Article | PubMed Abstract | PubMed FullText

29. Chukhlovin AB. Apoptosis and red blood cell echinocytosis: common features. Scanning microscopy. 1996; 10: 795-803.

30. Udden MM. Rat erythrocyte morphological changes after gavage dosing with 2-butoxyethanol: a comparison with the in vitro effects of butoxyacetic acid on rat and human erythrocytes. J Appl Toxicol. 2000; 20:381-7. | Article | PubMed

31. Quintanar-Escorza MA, Gonzalez-Martinez MT, Navarro L, Maldonado $M$, Arevalo $B$ and Calderon-Salinas JV. Intracellular free calcium concentration and calcium transport in human erythrocytes of leadexposed workers. Toxicol Appl Pharmacol. 2007; 220:1-8. | Article | PubMed

32. Ciccoli L, De Felice C, Paccagnini E, Leoncini S, Pecorelli A, Signorini C, Belmonte G, Valacchi G, Rossi M and Hayek J. Morphological changes and oxidative damage in Rett Syndrome erythrocytes. Biochim Biophys Acta. 2012; 1820:511-20. | Article | PubMed

33. Pretorius $\mathrm{E}$, Olumuyiwa-Akeredolu $\mathrm{OO}, \mathrm{Mbotwe} \mathrm{S}$ and Bester J. Erythrocytes and their role as health indicator: Using structure in a patient-orientated precision medicine approach. Blood Rev. 2016; 30:263-74. | Article | PubMed

34. Reddy KR, Reddy VD, Padmavathi P, Kavitha G, Saradamma B and Varadacharyulu NC. Gender differences in alcohol-induced oxidative stress and altered membrane properties in erythrocytes of rats. Indian J Biochem Biophys. 2013; 50:32-9. | PubMed

35. Chung LY. The antioxidant properties of garlic compounds: allyl cysteine, alliin, allicin, and allyl disulfide. J Med Food. 2006; 9:205-13. | PubMed

36. Avci A, Atli T, Erguder IB, Varli M, Devrim E, Aras S and Durak I. Effects of garlic consumption on plasma and erythrocyte antioxidant parameters in elderly subjects. Gerontology. 2008; 54:173-6. | Article | PubMed

37. Bayan L, Koulivand PH and Gorji A. Garlic: a review of potential therapeutic effects. Avicenna J Phytomed. 2014; 4:1-14. | PubMed Abstract | PubMed FullText

38. Sarkar A, Bhattacharjee D, Sengupta D, Paul S, Chowdhury KD, Sur PK and Sadhukhan GC. Delineating the Therapeutic Effectiveness of Allicin on Eryptosis During Chronic Pb2+ Exposure in Mice. Indian Journal of Applied Research. 2016; 5:2249-2555X.

39. Babu PV, Sabitha KE and Shyamaladevi CS. Green tea impedes dyslipidemia, lipid peroxidation, protein glycation and ameliorates $\mathrm{Ca} 2+$ -ATPase and $\mathrm{Na}+/ \mathrm{K}+$-ATPase activity in the heart of streptozotocindiabetic rats. Chem Biol Interact. 2006; 162:157-64. | Article | PubMed

40. Bharali MK, Saikia R. green tea extract inhibited lead acetate induced hemolytic changes in rat erythrocytes. International Research Journal of Pharmaceutical and Applied Sciences. 2015; 5: 7-11. | Pdf

41. Ghashghaeinia M, Cluitmans JC, Akel A, Dreischer P, Toulany M, Koberle M, Skabytska Y, Saki M, Biedermann T, Duszenko M, Lang F, Wieder T and Bosman GJ. The impact of erythrocyte age on eryptosis. Br J Haematol. 2012; 157:606-14. | Article | PubMed

42. Perrone S, Tataranno ML, Stazzoni G, Del Vecchio A and Buonocore G. Oxidative injury in neonatal erythrocytes. $J$ Matern Fetal Neonatal Med. 2012; 25:104-8. | Article | PubMed

43. El-Sokkary GH, Al Shaimaa Al and Atia MM. Protictive effects of green tea and garlic on the morphological and oxidative stress changes of hippocampus in aged male and female albino rats. Journal of Histology \& Histopathology. 2018; 5:1-9.

\section{Citation:}

El-Sokkary GH, A. I. Alghriany AS, and Atia MM. The protective role of green tea and garlic against the eryptosis induced by aging in albino rats. $J$ Histol Histopathol. 2018; 5:9.

http://dx.doi.org/10.7243/2055-091X-5-9 